\title{
Anaplastic Lymphoma Kinase-positive Primary Diffuse Large B-cell Lymphoma of the Larynx: A Rare Clinical Entity
}

\author{
Sudhir M Naik, A Nanjundappa, Rajshekar Halkud, CS Premlatha, C Ramarao, L Appaji, Sumit Gupta
}

\begin{abstract}
Background: Primary lymphomas amount to less than $1 \%$ of the primary laryngeal tumors. It is the second most common primary hematologic tumor of the larynx after plasmacytoma. Although squamous cell carcinoma amounts to $90 \%$ of the laryngeal tumors, diagnosis of laryngeal lymphoma is very important as nonsurgical management is indicated in all stages of this disease.
\end{abstract}

Case report A case of 10-year-old boy with hoarseness of voice with direct laryngoscopic biopsy reported as diffuse B-cell lymphoma. The sections were positive for epithelial membrane antigen (EMA), LCA, CD138, CD4 and Mum1 and ALK. He was managed under MCP 842 protocol. He had complete response after the treatment and was symptom free after 13 months of therapy.

Conclusion: Primary laryngeal lymphoma is a rare entity and should be managed with current chemotherapeutic protocol. Differentiating it between squamous cell carcinoma is important as management protocol in lymphoma is nonsurgical. Aid of immunohistochemistry helps in early diagnosis and management of these cases.

Keywords: Non-Hodgkin lymphoma, Supraglottis, Immunohistochemistry, MCP 842 protocol.

How to cite this article: Naik SM, Nanjundappa A, Halkud R, Premlatha CS, Ramarao C, Appaji L, Gupta S. Anaplastic Lymphoma Kinase-positive Primary Diffuse Large B-cell Lymphoma of the Larynx: A Rare Clinical Entity. IntJ Phonosurg Laryngol 2012;2(2):57-61.

\section{Source of support $\mathrm{Nil}$}

Conflict of interest: None declared

\section{INTRODUCTION}

Lymphoma is one of the most common malignancies of the head and neck, second only to squamous cell carcinoma. ${ }^{1,2}$ Primary lymphomas amount to less than $1 \%$ of the primary laryngeal tumors. ${ }^{3}$ It is the second most common primary hematologic tumor of the larynx after plasmacytoma. ${ }^{4-6}$ A lthough squamous cell carcinoma amounts to $90 \%$ of the laryngeal tumors, diagnosis of laryngeal lymphoma is very important as nonsurgical management is indicated in all stages of this disease. ${ }^{4-8}$

Lesser than 100 cases of primary laryngeal lymphoma are reported in world literature. ${ }^{9}$ They are mainly nonHodgkin lymphomas (NHL) and are commonly located in the supraglottic region, as this area of the larynx contains follicular lymphoid tissue. ${ }^{9} \mathrm{M}$ ost laryngeal lymphomas present as a submucosal mass or a polypoid tumor as a smooth, nonulcerated and gray-white lesion. ${ }^{3}$

They particularly involve the aryepiglottic folds of the supragl ottic larynx and are rarely reported in other laryngeal areas. ${ }^{10}$ Diffuse large $B$-cell type is the commonest among the N HL type primary laryngeal lymphomas while mucosaassociated lymphoid tissue type (M ALT) and marginal zone B-cell type are also reported. ${ }^{8}$ Early detection of lymphoma allows improved patient care and may result in decreased dissemination of the disease process. ${ }^{11,12}$

We report a case of diffuse $B$-cell lymphoma of the larynx presenting with hoarseness of voice in a young boy. Extensive M edline database search revealed only fewer cases of pediatric primary laryngeal lymphomas that are reported.

\section{CASE REPORT}

A 10-year-old boy was referred to us with complains of hoarseness since 6 months. He had undergone microlaryngeal excision biopsy of the lesion twice and the pathology was inconclusive on the first occasion and was reported as small round cell tumor on the second occasion. No complains of dysphagia, dyspnea or cervical lymphadenopathy was present.

On indirect laryngoscopy small polypoid submucosal supraglottic mass was seen. The lesion was nonulcerative bulge extending to the glottis and to the right pyriform fossa. Rest of the inlet of the larynx were normal with both the vocal cord moved on phonation. Microlaryngoscopic evaluation and biopsy found a smooth mucosal mass in the supraglottis extending to the right pyriform fossa.

Histopathological picture aided by immunohistochemistry came to the conclusion as anaplastic lymphoma kinase (ALK) positive diffuse B-cell lymphoma. The neoplastic cells were positive for epithelial membrane antigen (EM A), LCA , CD 138, CD 4 and M um1. A LK shows granular cytoplasmic positivity. They were negative for cytokeratin, desmin, CD 30, L M p1, M yoD 1, synaptophysin, chromogranin, S100, M elan A, CD3, CD57, CED 79a, and CD20 and Ki-67 proliferative index was around $60 \%$. A diagnosis of A LK-positive diffuse large B-cell lymphoma was made ( $F$ igs 1 to 3 ). Other investigations were in normal limits. 


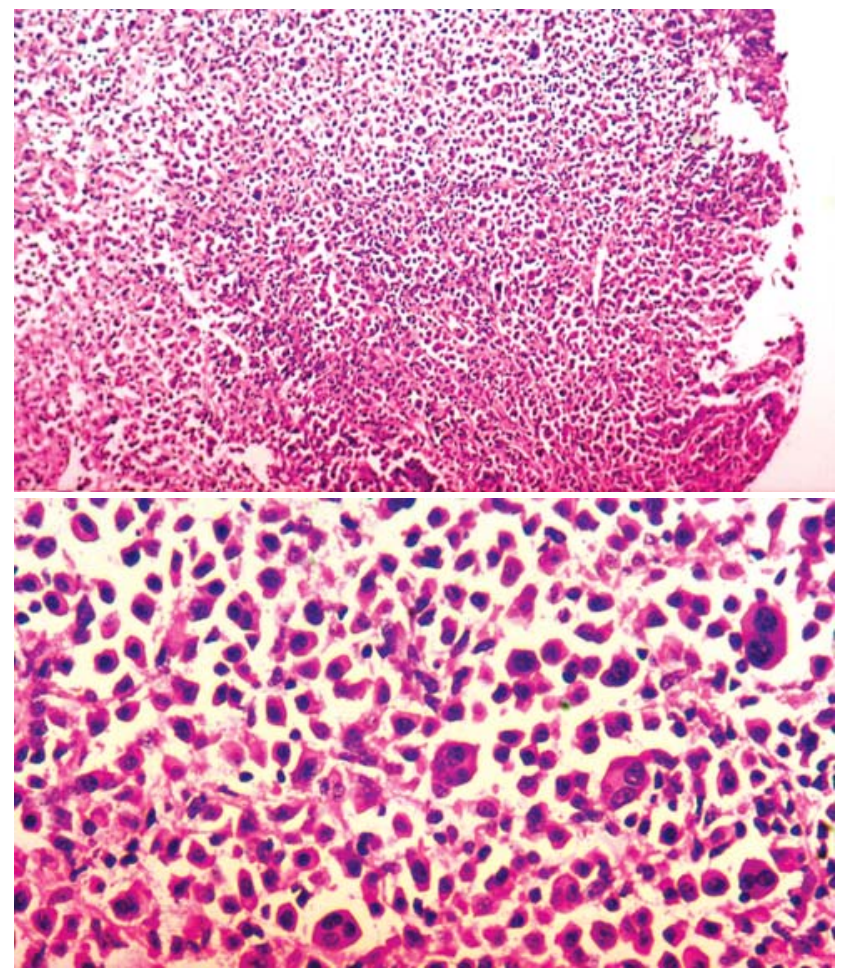

Fig. 1: Low and high magnifications of the diffuse large B-cell lymphoma

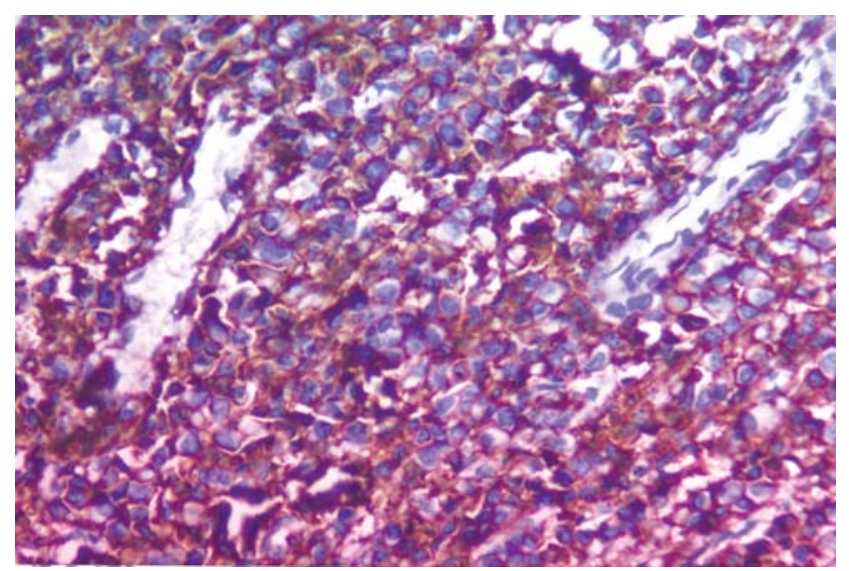

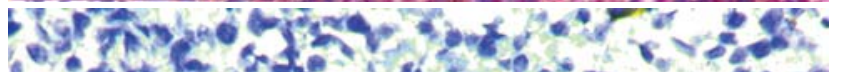

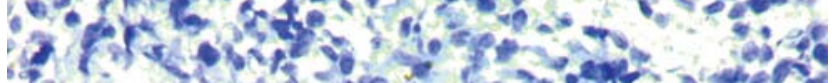

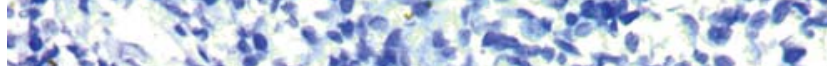

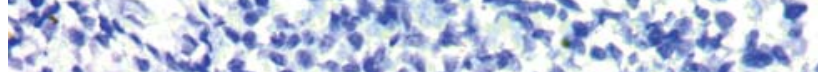

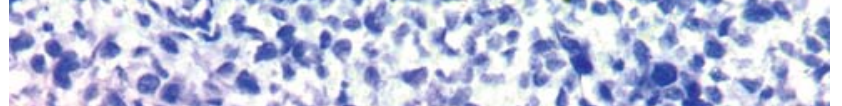

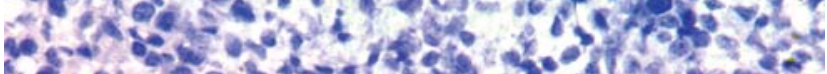

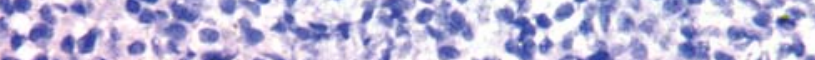

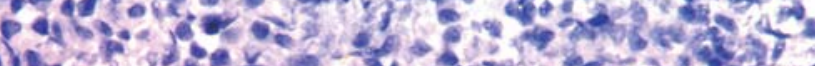

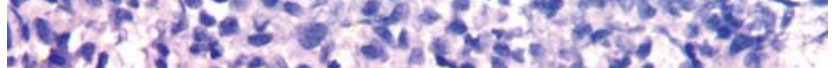

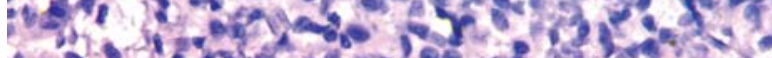

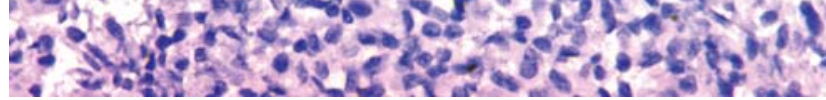

Fig. 2: Sections showing lymphocyte common antigen positive and negative to $C D 30$

Chest $X$-rays and soft tissue lateral neck $X$-rays were in normal limits (Fig. 4). Contrast enhanced computed tomography (CT) of neck reported an irregular

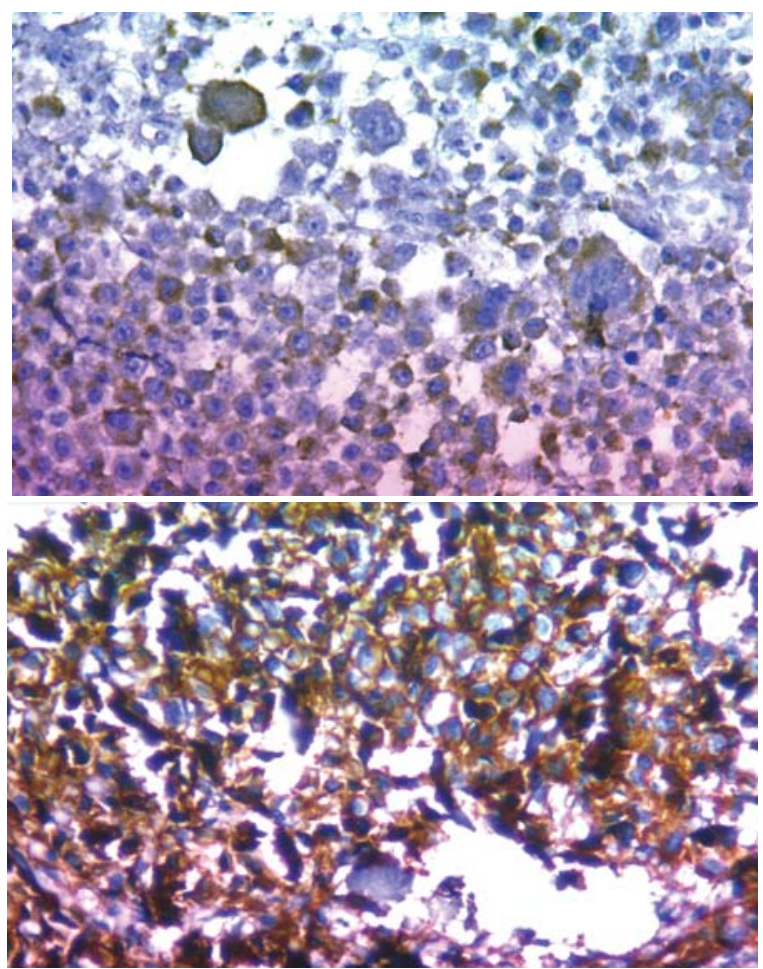

Fig. 3: Sections showing cytoplasmic granules positive for anaplastic lymphoma kinase and membrane positive CD 138

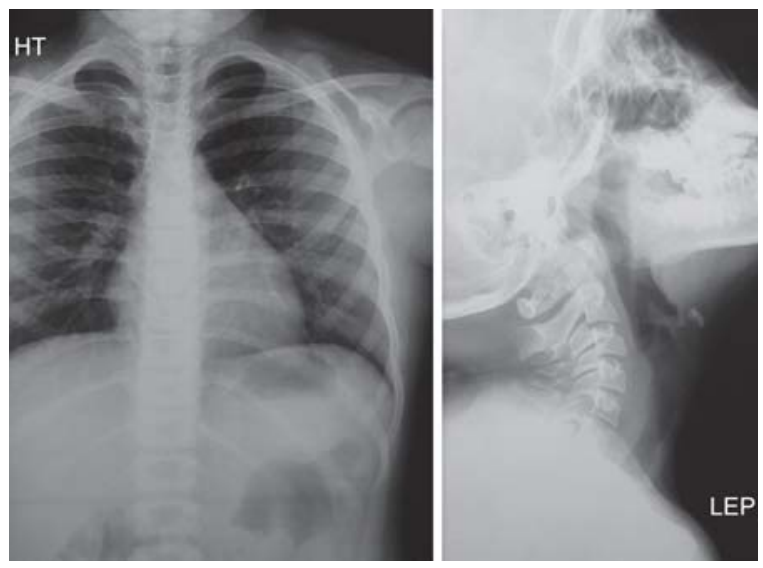

Fig. 4: Normal chest and neck X-rays

heterogeneously enhancing lesion in the right pyriform fossa extending to the right true and false vocal cords (Figs 5 and 6). Level $V$ on the right and left paratracheal lymph nodes were enlarged. Sonography of the abdomen was normal, with electrocardiogram showing biventricular hypertrophy and the echocardiography was normal with ejection fraction of $70 \%$.

A final diagnosis of the lesion was done as diffuse large B-cell lymphoma, stage IIE of the right supraglottis and extending to the pyriform fossa. The patient was managed under M CP 842 protocol. The advantages of the protocol include same chemotherapy course for all subsites, excellent tolerability, outpatient treatments, minimal supportive care needed, no total parenteral nutrition, minimal transfusion, growth factor and intravenous antibiotic requirements and 


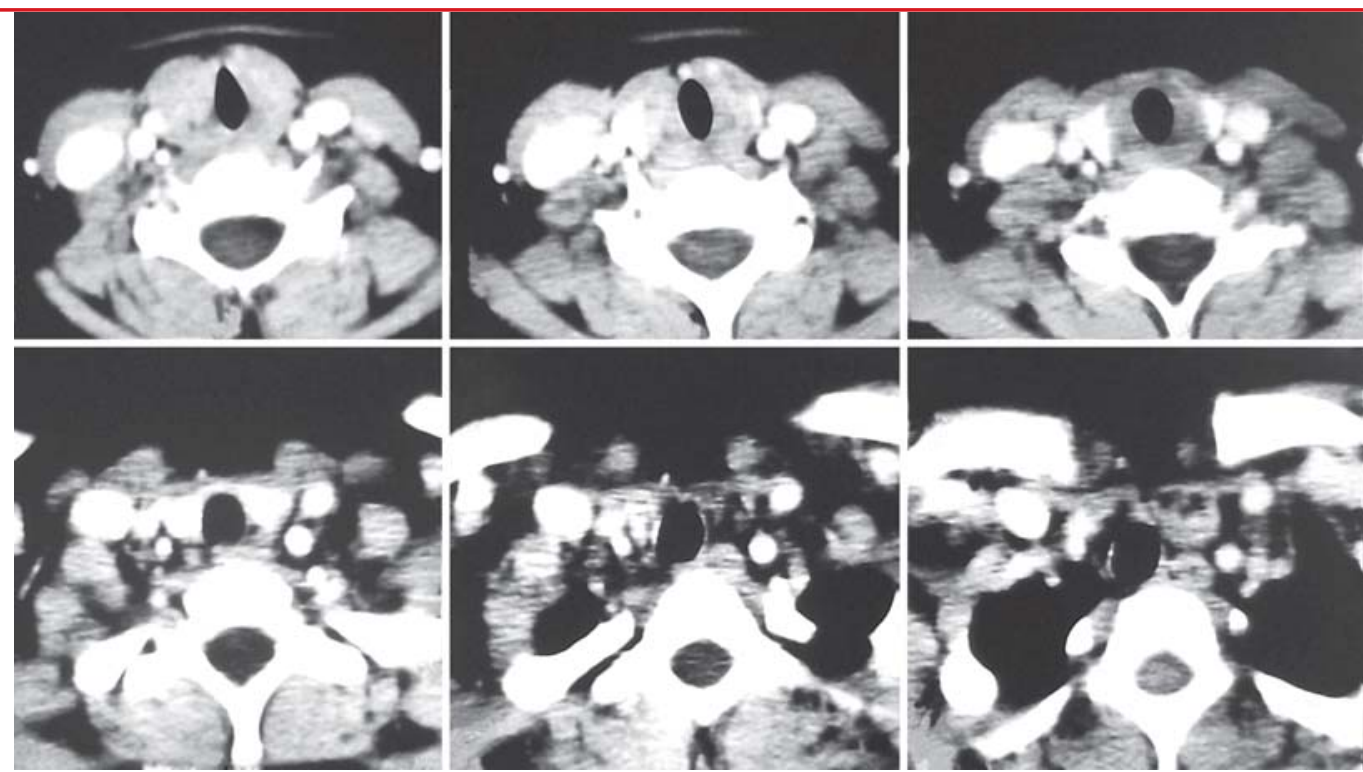

Fig. 5: Lesion seen in the right pyriform fossa and aryepiglottic folds
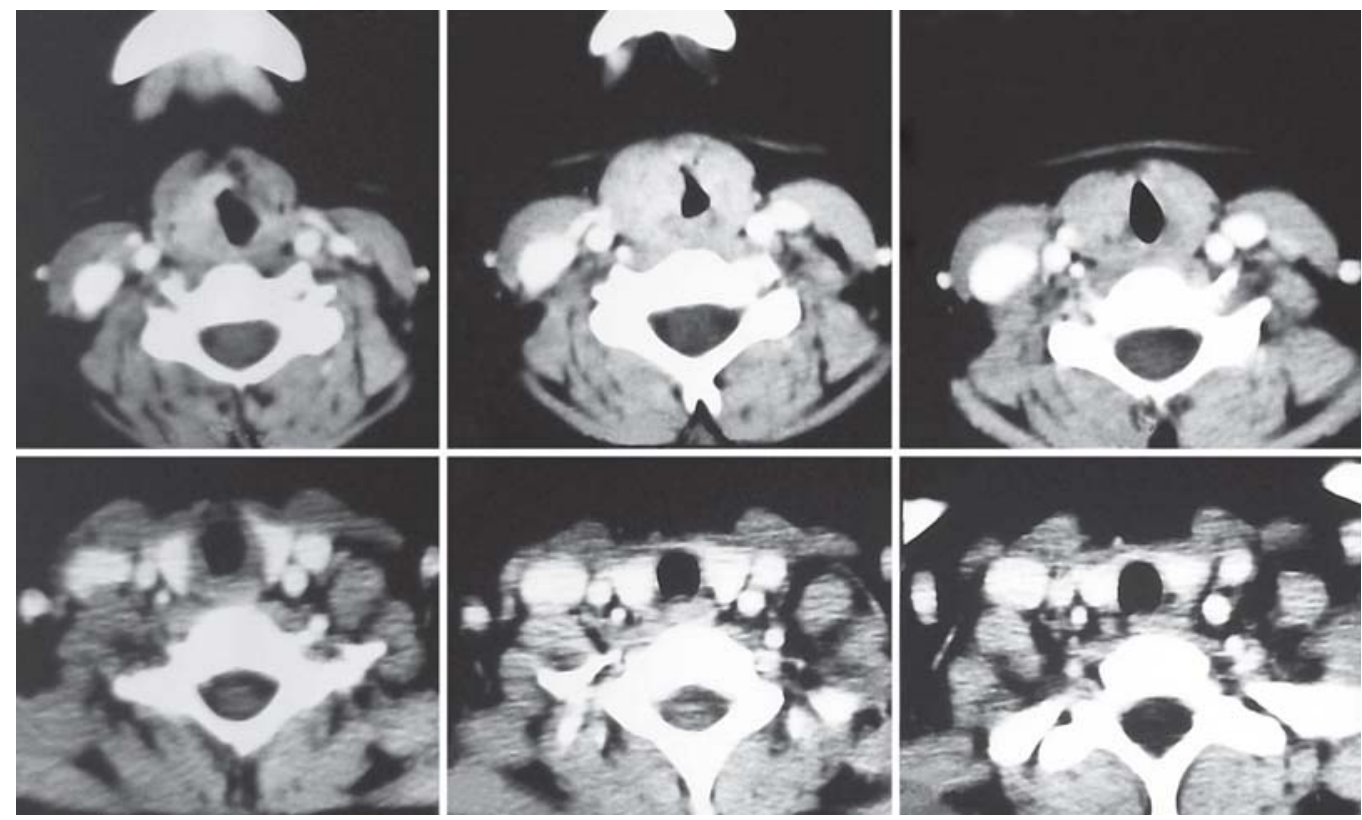

Fig. 6: Right level 5 lymph node and right paratracheal node significant enlargement seen

no radiotherapy is included in the protocol. The patient was reviewed after third cycle and then complete response was seen on laryngoscopic examination. The patient was symptom free for 13 months after therapy.

\section{DISCUSSION}

Malignant lymphomas are neoplastic transformations of lymphoid tissue with the Hodgkins and the non-Hodgkins as the two variants. ${ }^{3} \mathrm{M}$ ost of the lesions occur in the lymph nodes and extranodal involvement occurs only in $25 \%$ of the cases. ${ }^{1,3,13,14}$

NHLS amounts to the majority of the extranodal lymphomas in the head and neck region. ${ }^{15-18}$ Lymphoid aggregations in the Waldeyer's ring is the commonest site in the head neck region for extranodal lymphomas. ${ }^{15-18}$ Extranodal primary laryngeal NHLs account to less than $1 \%$ of the laryngeal neoplasms. ${ }^{3}$ U sually the laryngeal lymphomas are of a high grade and the low grade tumors are usually arising from M ALT. ${ }^{8,9} \mathrm{~A}$ ge ranges from 4 to 81 years, with mean age of occurrence at 7 th decade and the mean age 50 years. ${ }^{3,19} \mathrm{~V}$ aried sex predominance has been reported in different studies, ${ }^{3,7,19}$

Also other types of lymphomas, such as T- or natural killer (NK)-cell lymphomas are rarely reported. ${ }^{20,21}$ M ost lymphomas involving the larynx involve other sites containing lymphoid tissue extranodally like sal ivary glands, the thyroid, the nasopharynx and tonsils. ${ }^{3,8} \mathrm{U}$ sually the patients present with hoarseness, cough, dysphagia, a feeling 
of 'a foreign body sensation', stridor or systemic signs, such as weight loss and fever. ${ }^{3}$ Duration of the symptoms may vary from 10 days to 1 year. ${ }^{3}$ Primary laryngeal lymphomas pose a diagnostic challenge as they have no specific differential characteristics when compared to squamous cell carcinomas. ${ }^{3}$

Horny et al analyzed the published data and stated that most of these lesions are initially seen as nonulcerated smooth or polypoid masses in the epiglottis and the arytenoepiglottic folds. ${ }^{8,22}$ Subsite classification include $47 \%$ in supraglottis, $25 \%$ in glottis and rest present as subglottic or transglottic. ${ }^{3}$ Supraglottic region has rich lymphoid aggregations in the lamina propria so the higher incidence. ${ }^{3,23}$ The lesions in the glottis and subgl ottis present early as hoarseness and stridor. ${ }^{3}$ They remain localized for longer periods and may disseminate to distant mucosal sites rather than to peripheral lymphoid tissue with isolated recurrences in gastric mucosa, lung and orbit. ${ }^{24,25} \mathrm{M}$ arkou et al reported a synchronous occurrence of right vocal cord lymphoma and carcinoma in situ. ${ }^{3}$

Contrast-enhanced CT show a homogeneous lesion elevating the laryngeal mucosal surface. ${ }^{10} \mathrm{M}$ agnetic resonance imaging usually show varying densities lesion with high and intermediate signal intensity on $\mathrm{T} 2$-weighted images and homogeneous of intermediate signal intensity on T1-weighted images. ${ }^{10}$

These imaging modalities are helpful for assessment of laryngeal lymphoma but histopathological diagnosis aids in the final diagnosis. ${ }^{7}$ Deeper biopsies may be needed as superficial ones cannot distinguish safely the neoplastic from inflammatory cells. ${ }^{26,27}$

Primary laryngeal lymphomas usually show a intact overlying mucosa, benign appearing mass which can be differentiated from squamous cell carcinoma but has irregularity and ulceration involving the free margins of the laryngeal structures. ${ }^{28}$ Immunohistochemical analysis is required for accurate diagnosis as numerous antibodies are used to delineate the lymphoid nature of the cells and provide more specific information about the classification of B-cell or T-cell lineage subsets. ${ }^{3} \mathrm{~B}$-cell lymphomas amount to $70 \%$ of the cases among laryngeal lymphomas and T/NK-cell and MALT Iymphomas, are distinct clinicopathologic entities of laryngeal NHLs. ${ }^{3} \mathrm{~T} / \mathrm{NK}$ lymphomas are more seen in nasal and nasopharyngeal region while MALT lymphomas are seen in the stomach. ${ }^{3}$ Diebold et al described 15 cases of M A LT Iymphoma in larynx. ${ }^{29}$

$M$ anagement advised to include radiation and chemotherapy with low-grade lymphomas being radiosensitive and responding well to moderate-dose therapy (30-50 cGy)..$^{1,13,14}$ Combined modality treatment which includes radiotherapy plus chemotherapy or chemotherapy al one is very hel pful for recurrent or disseminated cases. ${ }^{30-32}$ Surgery has a role in the salvage modality only in laryngeal obstruction and massive hemorrhage. ${ }^{3} \mathrm{~K}$ ania et al reported MALT laryngeal lymphomas to be treated primarily by surgical excision. ${ }^{33}$ Flow cytometry and karyotypic analysis accurately helps in diagnosis and subclassification of lymphomas as well as in the determination of prognostic indicators by extensive cellular phenotypic characterization of the tumor specimen. ${ }^{3}$ This helps the oncosurgeons in creating patient-specific treatment protocols. ${ }^{3}$

Nayak et al described laryngeal lymphoma with extensive characterization of its tumor, leading to the application of a specific immunotherapeutic treatment. ${ }^{34}$ Five-year relapse free survival rate with current multimodality treatment is around 40 to $70 \%$ with no maj or meta-analysis done on the condition. ${ }^{35}$ Debulking of the tumor with $\mathrm{CO}_{2}$ laser has a role in slow-growing laryngeal lymphomas in postponing the definitive chemotherapy and radiotherapy for sometime. ${ }^{36,37}$ Dissemination to other extranodal sites, such as the upper respiratory tract, stomach, orbit, or skin, with a long disease-free interval are seen with radiotherapy and/or chemotherapy being effective for both primary and disseminated tumors. ${ }^{13}$

\section{CONCLUSION}

Primary laryngeal lymphoma is a rare entity and should be managed with current chemotherapeutic protocol. Differentiating it between squamous cell carcinoma is important as management protocol in Iymphoma is nonsurgical. A id of immunohistochemistry helps in early diagnosis and management of these cases.

\section{REFERENCES}

1. U rquhart A, Berg R. Hodgkin's and non-Hodgkin's lymphoma of the head and neck. Laryngoscope 2001;111:1565-69.

2. U rquhart A C. Lymphomas of the head and neck. In: Alper CM, $M$ yers $E N$, Eibling DE (Eds). Decision-making in ear, nose and throat disorders. New Y ork: W B Saunders 2001:306-07.

3. M arkou K, Goudakos J, Constantinidis J, Kostopoulos I, V ital $\mathrm{V}, \mathrm{Nikolaou} A$. Primary laryngeal lymphoma: R eport of 3 cases and review of the literature. Head Neck 2010 A pr 32(4): 541-49.

4. A nsell SM , H abermann TM , H oyer JD, et al. Primary laryngeal Iymphoma. Laryngoscope 1997;107:1502-06.

5. B rowne JD. M anagement of non-epidermoid cancer of the Iarynx. Otolaryngol Clin North Am 1997;30:215-29.

6. Anderson HA, Maisel RH, Cantrell RW. Isolated laryngeal Iymphoma. Laryngoscope 1976;86:1251-57.

7. King $A D, Y$ uen $E H$, Lei $K I$, et al. N on-Hodgkin lymphoma of the larynx: CT and M R imaging findings. A m J Neuroradiol 2004;25:12-15. 
Anaplastic Lymphoma Kinase-positive Primary Diffuse Large B-cell Lymphoma of the Larynx: A Rare Clinical Entity

8. Horny HP, Kaiserling E. Involvement of the Iarynx by hemopoietic neoplasms: A $n$ investigation of autopsy cases and review of the literature. Pathol Res Pract 1995;191:130-38.

9. Horny HP, Ferlito A, Carbone A. L aryngeal lymphoma derived from mucosa-associated Iymphoid tissue. Ann Otol Rhinol Laryngol 1996;105:577-83.

10. W ord R, U rquhart A C, Ejercito VS. Primary laryngeal lymphoma: Case report. Ear Nose Throat] 2006;85:109-11.

11. Zinzani PL, M agagnoli M, Galieni P, et al. N ongastrointestinal low grade mucosa-associated lymphoid tissue lymphoma: A nalysis of 75 patients. J Clin Oncol 1999;17:1254.

12. M arioni $G, M$ archese-R agona R, Cartei $G$, et al . C urrent opinion in diagnosis and treatment of laryngeal carcinoma. Cancer Treat Rev 2006;32:504-15.

13. M organ K, M acL ennan K A, Narula A, B radley PJ, M organ D A. Non-Hodgkin's lymphoma of the larynx (stage IE). Cancer 1989;64:1123-27.

14. Swerdlow JB, M erl SA, Davey FR, Gacek RR, Gottlieb AJ. Non-Hodgkin's Iymphoma limited to the Iarynx. Cancer 1984;53:2546-49.

15. Gleeson M J , B ennett M H, Caw son RA . L ymphomas of salivary glands. Cancer 1986;58:699-704.

16. Carbone A, Gloghini A, Ferlito A. Pathological features of lymphoid proliferations of the salivary glands: $L$ ymphoepithelial sialadenitis versus low-grade $B$-cell lymphoma of the M ALT type. A nn Otol R hinol Laryngol 2000;109(12 Pt 1):1170-75.

17. Sasai K, Y amabe H, K okubo M, et al. Head-and-neck stages I and II extranodal non-Hodgkin's lymphomas: Real classification and selection for treatment modality. Int J Radiat Oncol Biol Phys 2000;48:153-60.

18. Guermazi A, B rice $P$, de K erviler EE, et al. Extranodal Hodgkin disease: Spectrum of disease. Radiographics 2001;21:161-79.

19. Kato S, Sakura M, Takooda S, Sakurai M, Izumo T. Primary non-Hodgkin's Iymphoma of the Iarynx. J Laryngol Otol 1997;111:571-74.

20. M arianowski $R$, Wassef $M, A$ manou $L$, Herman $P$, Tran- $B$ aHuy P. Primary T-cell non-Hodgkin lymphoma of the larynx with subsequent cutaneous involvement. A rch 0 tolaryngol Head Neck Surg 1998;124:1037-40.

21. Hadjileontis CG, K ostopoulos IS, K al outsi V D, Nikolaou AC, K otoula VA, Papadimitriou CS. A n extremely rare case of synchronous occurrence in the larynx of intravascular lymphoma and in situ squamous cell carcinoma. Leuk L ymphoma 2003;44:1053-57.

22. Ho FC, Choy D, Loke SL, et al. Polymorphic reticulosis and conventional lymphomas of the nose and upper aerodigestive tract: A clinic-pathologic study of 70 cases, and immunophenotypic studies of 16 cases. H um Pathol 1990; 21:1041-50.

23. M acK enty JE. M alignant disease of the larynx. A rch O tolaryngol 1934;20:297-328.

24. Podoshin L, Fradis M , Schal it M . L ymphosarcoma of the larynx. J Laryngol Otol 1971;85:1063-68.

25. Dogra TS. Lymphosarcoma of Iarynx. J Laryngol Otol 1972;86:535-41.

26. Mok JS, Pak M W, Chan KF, Chow J, Hasselt CA. Unusual T and T/NK-cell non-Hodgkin's lymphoma of the larynx: A diagnostic challenge for clinicians and pathologists. H ead N eck 2001;23:625-28.

27. M onobe $H, N$ akashima $M$, Tominaga $K$. Primary laryngeal natural killer/T-cell lymphoma - report of a rare case. Head N eck 2008;30:1527-30.
28. M acL ennan KA, Schofield JB. Haemopoietic neoplasms. In: Ferlito A (Ed). N eoplasms of the larynx. N ew Y ork: Churchill Livingstone 1993:327-36.

29. Diebold J, A udouin J, V iry B, Ghandour C, B etti P, D'Ornano G. Primary lymphoplasmacytic lymphoma of the larynx: A rare localization of MALT-type Iymphoma. Ann Otol Rhinol Laryngol 1990;99(7 Pt 1):577-80.

30. W ang CC. M alignant lymphoma of the larynx. Laryngoscope 1972;82:97-100.

31. Ghosh KC, Chatterjee D N, M ukherjee D, M ondal A, M ukherjee $A L$. Primary non-Hodgkin's lymphoma of larynx (a case report). J Postgrad M ed 1986;32:103-04.

32. Cohen SR, Thompson JW, Siegel SE. N on-Hodgkin's lymphoma of the larynx in children. Ann Otol Rhinol Laryngol 1987; 96:357-61.

33. K ania RE, Hartl DM, Badoual C, Le M aignan C, Brasnu DF. Primary mucosa-associated lymphoid tissue (M A L T) lymphoma of the larynx. Head Neck 2005;27:258-62.

34. Nayak JV, Cook JR, M olina JT, et al. Primary lymphoma of the larynx: New diagnostic and therapeutic approaches. ORL J Otorhinolaryngol Relat Spec 2003;65:321-26.

35. B rusamolino E. First line therapy of CD20+ diffuse large Bcell Iymphoma: Facts and open questions. Hematologica 2009;94(9):1194-98.

36. B radley $\mathrm{PJ}$. Treatment of the patient with upper airway obstruction caused by cancer of the larynx. Otolaryngol Head Neck Surg 1999;120:737-41.

37. Paleri V, Stafford FW, Sammut M S. Laser debulking in malignant upper airway obstruction. Head Neck 2005;27: 296-301.

\section{ABOUT THE AUTHORS}

\section{Sudhir M Naik (Corresponding Author)}

Fellow, Department of Head and Neck Oncosurgery, K idwai Memorial Institute of Oncology, Bengaluru, Karnataka, India e-mail: sud223@gmail.com

\section{A Nanjundappa}

Professor, Department of Head and Neck Oncosurgery, Kidwai M emorial Institute of Oncology, B engaluru, Karnataka, India

\section{Rajshekar Halkud}

Associate Professor, Department of Head and Neck Oncosurgery Kidwai M emorial Institute of Oncology, B engal uru, K arnataka, India

\section{CS Premlatha}

Associate Professor, Department of Pathology, Kidwai M emorial Institute of Oncology, B engaluru, Karnataka, India

\section{Ramarao}

Professor, Department of Pathology, K idwai M emorial Institute of Oncology, B engaluru, K arnataka, India

\section{Appaji}

Professor, Department of Pediatric Oncology, Kidwai M emorial Institute of Oncology, B engaluru, Karnataka, India

\section{Sumit Gupta}

Fellow, Department of Head and Neck Oncosurgery, K idwai M emorial Institute of O ncology, B engaluru, Karnataka, India 